\title{
ENVERDECER LAS CIENCIAS JURÍDICAS DESDE EL PARADIGMA DE LA COMPLEJIDAD
}

\author{
Taeli Raquel Gómez ${ }^{1}$ \\ Universidad de Atacama (UDA)
}

\section{RESUMEN}

Este artículo aspira a dar cuenta de la importancia que significa replantear a las ciencias jurídicas desde una base no antropocéntrica y dar sentido a una revisión de pilares epistemológicos y modelos teóricos que, a pesar de cambios legislativos con contenido ambiental, no alcanzan un planteamiento transversal en las ciencias jurídicas. La propuesta del enverdecimiento de las ciencias jurídicas representa el resultado de una configuración que parte de una noción relacional humana-no humana como parte fundamental de nuevos significados y por ende, de nuevos fundamentos complejos para la elaboración del derecho como su objeto de estudio. La metodología es la dialéctica y va desde una etapa de acumulación como manifestación de la incorporación de la problemática ambiental al derecho pasando por una de contradicción, integración y de síntesis, como salto cualitativo que propone el enverdecimiento de las ciencias jurídicas.

Palabras clave: ciencias jurídicas; medio ambiente; paradigma complejo.

\section{ECOLOGIZAR AS CIÊNCIAS JURÍDICAS: UMA ABORDAGEM A PARTIR DA TEORIA DA COMPLEXIDADE}

\section{RESUMO}

Este artigo tem como objetivo (re)significar as ciências jurídicas a partir de sua base antropocêntrica e compreender uma revisão dos pilares epistemológicos e modelos teóricos que, apesar das mudanças

1 Doctora en Ciencias Filosóficas por la Universidad de La Habana (UH). Abogada y licenciada en Ciencias Jurídicas por la Universidad Nacional Andrés Bello (UNAB). Profesora titular de Filosofía del Derecho en la UDA. ORCID: http://orcid.org/0000-0001-8081-1417 / e-mail: taeli.gomez@uda.cl 
legislativas com conteúdos ambientais, não alcançaram êxito no processo de transversalização das ciências jurídicas. A proposta de ecologização das ciências jurídicas representa o resultado de uma configuração que parte de uma noção relacional humano-humano como parte fundamental de novos significados e finais, de fundamentos completos para a elaboração do direito como objeto de estudo. A metodologia é dialética e vai de um estágio de acumulação como manifestação da incorporação de problemas ambientais no direito; passando por uma contradição, integração e síntese, como um salto qualitativo que promove a ecologização das ciências jurídicas.

Palavras-chave: ciências jurídicas; meio ambiente; paradigma completo. 


\section{INTRODUCCIÓN}

Las sociedades actuales se encuentran enfrentadas a riesgos de sobrevivencia. Hay alarmantes estudios que lo refuerzan y ofrecen cifras sobre la pobreza mundial; como lo revela el Índice de Pobreza Multidimensional Global (IPM), publicado por el Programa de las Naciones Unidas para el Desarrollo (PNUD); la Lista Roja de Especies Amenazadas de la UICN a lo largo del mundo; las múltiples ONG y organizaciones que denuncian poder contra la naturaleza y la vida, dejando al descubierto el actual escenario. Lo anterior evidencia la probabilidad de extinción de la especie humana, lo cual lejos de ser una alarma sin fundamento, hoy se vuelve una posibilidad cercana y necesidad para transformaciones profundas.

En esa línea, las crisis ambientales y cómo ellas impactan en las dinámicas sociales, representan uno de los problemas más complejos que se viven en la actualidad. Frente a este contexto, las ciencias jurídicas deben ofrecer estrategias de innovación para enfrentar el estadio contradictorio de la relación sociedad-naturaleza-naturaleza-sociedad. Principalmente, con el propósito de reconocer el componente sistémico y no-lineal ineludible de esta relación y el desafío de incorporar un pensamiento que fortalezca un pensar desde la interrelación, la asociación y relación.

Para ello, las ciencias jurídicas deben ser revisadas en su calidad de colaboradoras de las bases actuales de la organización jurídico-política y el jurista como agente de cambio debe habilitar el debate crítico sobre sus paradigmas conservadores como proceso de autorreflexión. Principalmente, por lo extraño que resulta, que a pesar de la trascendencia de estos temas, no han alcanzado la envergadura generalizada del debate socio jurídico. Ello porque la atención ha estado más bien enfocada a nivel de analizar la legislación y del legislador como agente de cambio, lo que ha restado compromiso teórico al interior de las comunidades científicas; pues no siempre se revisa la insuficiencia de los modelos, paradigmas y bases teóricas que dependen de las comunidades científicas. En tal sentido, a estas se les debe interpelar respuestas sobre, ¿a qué proyecto de sociedad se quiere contribuir? y con ello, ¿cómo participar desde su ámbito a dar soluciones a las problemáticas del mundo actual?

De ahí entonces, este trabajo se propone partir de las interrogantes 
¿las ciencias jurídicas frente a las crisis ambientales y el estadio de relación contradictoria sociedad-naturaleza-naturaleza-sociedad, se mantienen en la pasividad de soluciones parciales confiando en la proactividad del legislador? o bien, ¿las ciencias jurídicas desde su propia actividad científica, están en condiciones de revisar sus bases epistemológicas, paradigmas, teorías y modelos que signifiquen la revisión de las bases que organizan su conocimiento jurídico, para profundizar en la relación compleja sociedad-naturaleza-naturalezasociedad?

El objetivo del presente trabajo, es hacer una revisión a los modelos y supuestos teóricos y paradigmas que mantienen los fundamentos antropocéntricos y no eco-sociales presente en las ciencias jurídicas $\mathrm{y}$, de esta manera, hacer una propuesta para enverdecer a las ciencias jurídicas.

En este sentido, la idea central que desarrolla este artículo, no sólo está orientada a demostrar que las crisis ambientales son una fuente de problemáticas científica para las ciencias jurídicas, sea de revisión legislativa, de creación de principios y elaboración de modelos jurídicos; sino que además, ponen en cuestión la presencia de un paradigma clásico o de simplicidad como la estrategia para abordar jurídicamente la problemática ambiental. Principalmente, ha estado presente en la fragmentación de la temática y en mantener el enfoque antropocéntrico; como asimismo, en la presencia del pensamiento objetual, atomista y de algún modo fragmentado con el que se abordan las temáticas.

De ahí entonces, este trabajo se propone incorporar los aportes del paradigma científico denominado complejo o de las complejidades, el que ha venido a concebir cambios en la relación epistémica sujeto-objeto de conocimiento, en especial con la epistemología de segundo orden, que integra al sujeto como investigador en el objeto como sujeto en proceso reflexivo, según aportan Sotolongo y Delgado (2006). También se replantea desde una nueva noción de realidad dinámica como regularidades emergentes, sin restricciones a finales fijos, considerando los aportes de Varela (2006). Para asimismo, adoptar la conexión que significan las categorías de sistemas complejos, tanto para el estudio de lo social y natural, como propone García (2006). Y además validar los aportes provenientes de la trama de vida y los modelos conceptuales complejos de Capra $(1992 ; 1998)$.

En consecuencia, se incorpora la reflexión de nuevos pensamientos para abordar estas nuevas nociones, como el Pensamiento Complejo 
que propone Morin y que principalmente reconoce a los objetos de estudio y sus problemáticas de manera compleja, en interrelaciones con sus diálogos y contradicciones, considerativo de las dinámicas de movimiento entre el todo-parte-parte-todo de manera no lineal, sino en bucles de recursividad (MORIN, 2003). Este pensamiento complejo debe contribuir a las ciencias jurídicas a replantear sus enfoques e inclusive, sus manera de hacer crítica jurídica (GÓMEZ, 2012b), en especial a para estar a la altura y coherencia con la profundidad de la crisis ambiental.

Asimismo, las ciencias jurídicas cuando validan epistemologías que integran al sujeto como investigador presente en el objeto, no sólo hacen el ejercicio de describir las normas jurídicas, sino que incorporan subjetividad, o como dice Valle (2006), admite que hay una cultura jurídica interna que implica un dominio subjetivo de la experiencia jurídica que media a través de modelos teóricos, maneras de pensar el derecho, determina paradigmas y supuestos de lecturas e interpretaciones. Como señala Atienza, suministra criterios para la producción y aplicación del Derecho (ATIENZA, 2016). Es decir, cada vez que se clasifica, se valora o compara, se seleccionan criterios y además, se define y construye al objeto de estudio con el aporte de modelos y paradigmas científicos, lo que invita a la necesidad de formular una respuesta más coherente al tema ambiental que expresa la relación sociedad-naturaleza-naturaleza-sociedad y ciencias jurídicas.

Para el desarrollo metodológico se utilizará el saber omnicomprensivo de la Filosofía y del paradigma científico de la complejidad, para hacer la revisión de las esencias y las dinámicas de sus relaciones transversales y de las limitantes teóricas. Pasando desde la revisión de un movimiento particular de inicio de estadios y conciencia jurídica ambiental; para avanzar hacia la revisión analítica de los a priori, de las categorías y de las tramas al interior de las ciencias jurídicas, como proceso de acumulación cuantitativa de la problemática ambiental en el derecho. Posteriormente, se pasa a una etapa integradora de enverdecimiento de las ciencias jurídicas, como la representación de un salto cualitativo, principalmente, como propuesta jurídica de una estrategia para producir conocimiento jurídico innovadora, con aspiración hacia la sobrevivencia.

Para ello se ha utilizado bibliografía que aporta con teorías relacionales para la revisión crítica de perspectivas reduccionistas. Entre los 
autores utilizados está Malpartida (2004), quien señala que la tendencia en nuestro lenguaje es objetualizar, cosificar, sustancializar, lo que se ha apoyado por un paradigma clásico de simplicidad, que en palabras de Morin (2003, p. 55),

[...] ve a lo uno y ve a lo múltiple, pero no puede ver que lo Uno puede, al mismo tiempo, ser Múltiple. El principio de simplicidad o bien separa lo que está ligado (disyunción), o bien unifica lo que es diverso (reducción).

Para ello se valoran los aportes de las perspectivas de la complejidad que propone Capra, como su propuesta de las tramas de la vida y de giro epistemológico.

\section{ETAPA DE ACUMULACIÓN: INCORPORACIÓN DE LA PROBLEMÁTICA AMBIENTAL AL DERECHO Y LA LIMITACIÓN DEL PARADIGMA CLÁSICO PARA INNOVAR}

Hay que reconocer que desde hace mucho tiempo, se han regulado temáticas que hoy serían consideradas materias ambientales; como las regulaciones sobre el agua que ya se daban desde 1831 (OBANDO-CAMINO, 2009) e incluso en el Digesto ya se planteaba (MUÑOZ, 2014); o en general, las distintas gestiones normativas destinadas a frenar los efectos negativos sobre la salud y medio ambiente (CAMACHO, 2010). Estas eran estrategias orientadas a dar respuesta a una problemática particular y no en el contexto de una conciencia ecológica global como la que surge a mediados y fines del siglo XX, por lo que podrían constituir antecedentes remotos para esta etapa.

- Fase de alerta previa con enfoques parciales, compromiso legislativo: en cuanto a lo que se ha denominado etapa de acumulación de la incorporación de la problemática ambiental al derecho, se puede reconocer un proceso que comienza con una fase de alerta previa con enfoques parciales. Esta, implica una acumulación cuantitativa de normas jurídicas -leyes especiales, Tratados internacionales, reglamentos, ordenanzas y todo tiempo de regulaciones sobre la temática-, que han ido incorporándose al derecho como una necesidad por controlar comportamientos humanos, sea en el ámbito del hacer, del no hacer y de las responsabilidades frente a la naturaleza. Ello podría considerarse, en buena medida, como un mecanismo de control social respecto de ámbitos parciales (contaminación, restricciones, 
consumo, caza, etc.). Esta fase, está más bien orientada a dar respuestas normativas, donde el agente de cambio comprometido es el legislador.

- Fase de integración, el derecho ambiental y compromiso del jurista: esta representa un momento de síntesis y parte de un proceso de acumulación normativa y de respuesta significativa; un estadio de mayor grado de unificación y pretensión por abordar de manera integral, la problemática de la relación sociedad-naturaleza. Aquí se sitúa el surgimiento de una nueva rama conocida como Derecho ambiental, definida como “...el sistema jurídico ambiental con el sistema de normas, reglas de conducta, principios, normas sociales y costumbres, y documentos escritos en general, en sus diferentes niveles o instancias: internacional, nación, provincia y local" (FERNÁNDEZ-RUBIO, 2006). Ello, sin considerar las variadas otras conceptualizaciones que se han dado por parte de la doctrina nacional e internacional que se pueden encontrar en los nutridos manuales que hoy existen del área, como la de Fernández que considera al derecho como una ciencia que regula las acciones de conducta de la sociedad, y desde ahí señala en su primera parte, que el derecho ambiental es un conjunto de principios, leyes, normas y jurisprudencia que regulan la conducta humana dentro del campo ambiental (FERNÁNDEZ, 2004), también definido como una disciplina jurídica que se compone de un conjunto de normas regulatorias de relaciones de derecho público y privado que disciplinan el uso racional y conservación del medio ambiente (CAFFERATTA, 2004), o bien para lograr equilibrio entre las relaciones del hombre y el ambiente al que pertenece, a fin de lograr un ambiente sano y el desarrollo sostenible (ANDALUZ, 2006).

Esta nueva rama de especialización que surge como nueva organización de conocimiento al interior de las ciencias jurídicas, se comienza a perfeccionar desde la aprobación de la Declaración sobre el Medio Humano, Estocolmo 1972. Este estadio detona un fructífero proceso jurídico, tanto por la creación, desarrollo y proliferación de normas jurídicas que van desde las nacionales de alta jerarquía, como las constituciones que asumen el tema desde distintas posibilidades y perspectivas ${ }^{2}$; como una

2 A manera de ilustración, la Constitución de Grecia en 1975, la cual señala que es obligación del Estado la protección del ambiente natural y cultural, modificada posteriormente; luego la Constitución de la República portuguesa de 1976 que menciona en su artículo 66 del ambiente y la calidad de vida; la Constitución española de 1978, que no sólo establece el derecho a disfrutar de un medio ambiente, sino también consagra el deber de conservarlo. En América se puede reconocer a la Constitución de Panamá 1972, Cuba 1976, Perú 1979, El Salvador 1983, Nicaragua 1986, Colombia 1991, sin mencionar a las evolucionadas protecciones a la naturaleza que realizan las constituciones de la República del Ecuador 
variada e importante inclinación hacia la generación de normativa internacional, que da cuenta que los problemas ambientales, son de aquellos que traspasan las fronteras. Entre muchas podemos recordar emblemáticas como el Convenio de Viena para la Protección de la Capa de Ozono, aprobada en 1985; Convenio de las Naciones Unidas sobre el Derecho del Mar de 1982; sobre la Diversidad Biológica 1992; la Convención Marco de las Naciones Unidas sobre Cambio Climático 1992; Declaraciones como las de Río 1992; y Protocolos como Kioto de 1998.

Sin embargo, esta fase ya no solo involucra al legislador, sino que a las ciencias jurídicas, a la actividad científica del jurista. Esto implica un proceso teórico que se traduce en una estrategia para comprometer participación en el contexto de la crisis ambiental -presente y riesgo futuro-. En primer lugar, se trata de un seguimiento, análisis normativo, ordenación y elaboración de principios de todo un conjunto de normas que regulan relaciones humanas, tanto en la consideración de acciones y omisiones que contaminan o afectan ecosistemas.

En segundo lugar, esta disciplina también trata de la reflexión de sí misma, de su naturaleza. Así por ejemplo, Astorga, caracteriza al Derecho ambiental como un sustratum ecológico, es decir, que al ser su objeto protegido el medio ambiente, es de especialidad singular, donde el ámbito de aplicación de la norma no puede ajustarse a los límites de las fronteras, con énfasis preventivo, con un componente técnico reglado que se nutre desde distintas especialidades, con vocación retributiva relacionado con el principio de quien contamina paga y con primacía e intereses colectivos (ASTORGA, 2005).

$\mathrm{Y}$ en tercer lugar, esta fase de integración, la acumulación va adquiriendo una connotación particular de producción dogmática y de profundización teórica; especialmente con la formación de una comunidad científica especializada; a través de postítulos y postgrados, tanto doctorados y maestrías en el área; una red de Encuentros científicos a través de Congresos, Jornadas, Simposios y otros; de una gama de Revistas especializadas, sólo por ilustrar su desarrollo.

- Fase de generalización y profundización: ya no solo hay una profundización de la disciplina del derecho ambiental, sino también se produce una generalización a casi todas las ramas del derecho, las cuales han comenzado a admitir la problemática ambiental desde sus distintas esferas y particularidades, incluyéndola en sus tramas categoriales y debates 
doctrinarios. Así por ejemplo, el Derecho Público Nacional e Internacional ha sido uno de los principales recepcionistas de la temática ${ }^{3}$; en Derecho Penal se debaten las nuevas consideraciones o nuevos bienes jurídicos como el ambiental (OCHOA, 2014; MATUS ACUÑA et al., 2003), nuevos delitos ambientales, nuevas jurisdicciones internacionales (MOSCOSO, 2014); también en el Derecho civil aparece la temática de responsabilidad extracontractual por daño ambiental (MEDINA; AGUIRRE; SARANGO, 2017); en el Derecho Constitucional el área de los recursos o acción de protección o amparo como, artículo 20 de la Constitución Política de la República de Chile; y de igual manera está toda la gama del neoconstitucionalismo latinoamericano, con los aportes de las constituciones de Bolivia, Venezuela, Ecuador y Colombia. Autores connotados también han comenzado a asumir parte relevante del tema como Zaffaroni con su texto La Pachamama y el humano; donde señala que a pesar de los avances con bienes jurídicos diferentes a los conocidos y la creación de tipos penales, no se desvincula de lo humano (ZAFFARONI, 2011).

Sin embargo, a pesar del avance de estas fases, el proceso dialéctico de incorporación de normas nacionales e internacionales, aún de las más altas jerarquías y sus cambios cualitativos, incluyendo debates relevantes de juristas, aún se mantiene un pensamiento reduccionista y enfoque subdisciplinario como estrategia de abordar la problemática sociedad-naturaleza por parte de las ciencias jurídicas. No hay conexión entre distintas áreas jurídicas. En razón de lo anterior, este artículo propone un salto cualitativo de incorporación de la relación humano-no humano como una aventura más profunda y con mayores repercusiones para las ciencias jurídicas. El aporte del paradigma de las complejidades permite incorporar a las ciencias jurídicas, perspectivas y enfoques sistémicos e integradores.

Finalmente, en cuanto a esta etapa, se puede sostener desde el punto de vista epistemológico, que las ciencias jurídicas mantienen pilares antropocéntricos y paradigmas mecanicistas clásicos que sirven de base a la elaboración de su conocimiento jurídico. Entre algunas

3 "Conferencia Internacional sobre la utilización racional y la conservación de los recursos de la Biosfera" conocida como la "Conferencia de la Biosfera", celebrada en París, 1968, organizada por la UNESCO, en colaboración con las Naciones Unidas; la Organización de las Naciones Unidas para la Agricultura y la Alimentación, FAO; la Organización Mundial de la Salud, OMS y el Programa Biológico Internacional del Consejo Internacional de Uniones Científicas y la UIC; la Conferencia sobre el Medio Humano, realizado en Suecia, Estocolmo, 1972; La Cumbre de la Tierra de Río de Janeiro, Brasil, de 1992; la Cumbre Mundial para el desarrollo sostenible en Johannesburgo, Sudáfrica, 2002. Además de la prolífera gama temática de Cumbres; sobre cambio climático, humedales etcétera. 
evidencias figuran: (a) la relación epistemológica dual sujeto-objeto de conocimiento que promueve e impulsa el desarrollo de un Derecho incompatible con la consideración de la unidad humano-no humano (GÓMEZ, 2009); (b) la noción de un objeto de estudio normativista como algo como entidad final "hecha", "acabada", "dada" y no dinámica como el devenir humano-no humano; (c) la concepción de un objeto de estudio que se caracteriza por el grado de determinismo, causalidad y de predicción que descontextualizan el movimiento vivo (GÓMEZ, 2011). De igual manera se apoya de un pensamiento analítico, más bien reduccionista y objetual.

\section{ETAPA DE INTEGRACIÓN SISTÉMICA}

Esta etapa se puede comprender como un desarrollo más profundo e integrado de concepciones complejas de la naturaleza y de la vida; de la articulación e interdependencia con otras disciplinas; de la consolidación de pensamientos más bien post clásicos, complejos y sistémicos. Todo lo que implica un movimiento inverso, donde ya no solo basta la especialización, sino un diálogo abierto inter-multi y trans disciplinario, y por ende, de incorporación de nuevos paradigmas coherentes con esta necesidad.

De acuerdo a cómo ha evolucionado la temática, existen algunas consideraciones que promueven una perspectiva de pensamiento sistémico e integrador respecto de lo que puede ser momentos dialécticos de síntesis. En especial, porque van más allá de cambiar la legislación sobre la temática o por la elaboración dogmática presente en el Derecho ambiental. El énfasis está en la autoconciencia que esta especialidad, ha ido adquiriendo y que promete nuevas e integradoras reflexiones, en especial la búsqueda de ideologías o planteamientos que permitan comprender fundamentos que inspiran al derecho o a las ciencias jurídicas y su relación con un pensar ecologizado.

En esta línea se ha estudiado el impacto que pueden tener los postulados ecologistas en las normas jurídico-positivas y consideraciones doctrinales. En este sentido, se ha reconocido que si bien el ecologismo es fundamento del derecho a un medio ambiente sano, lo es aún de manera moderada (BADULES, 2015). No se debe pasar por alto las nuevas propuestas de Zaffaroni, quien advierte, que si bien se plantea al ecologismo jurídico como una posibilidad más comprometida a reconocer al ambiente como bien jurídico, aún no se ha logrado un avance de conciencia en su 
interior; y que sin embargo, el ambientalismo jurídico, es un enfoque más moderado que entiende que el medio ambiente sano es un derecho humano (ZAFFARONI, 2011).

Por su parte Lorenzetti, ya refiere a la presencia de un paradigma ambiental y que discurre en tres fases cronológicas, la retórica con un avance del movimiento ambientalista; la analítica que incorpora estudios científicos y que está impacta en lo jurídico, pues de ella se desprende el desarrollo de las normas jurídicas nacionales e internacionales; y la tercera paradigmática como una mutación epistemológica que desplaza la visión antropocéntrica. Y señala que hay un distintivo sui generis del paradigma ambiental, que reconoce a la naturaleza como sujeto de derecho (LORENZETTI, 2008).

Otro ámbito podría desarrollarse a una apertura de temáticas de connotación más inclusivas y relacionales que podrían integrar sistémicamente a las ciencias jurídicas, donde podría estar la noción de Justicia ambiental. Hoy entendida como el acceso equitativo a los beneficios derivados del uso de los recursos naturales entre los miembros de la comunidad global y un reparto igualmente equitativo de las cargas (DONOSO, 2018); o bien, también definida como un desafío a dar un relato a las modificaciones normativas y una lógica sistémica a ellas y a su relación con la regulación actual (COSTA, 2017), lo que las ciencias jurídicas podrían profundizar y generalizar sus principios y ampliarlos como base de consideración de la Justicia. También han surgido nociones de participación ciudadana que abren una posibilidad a integrar lo social-ambiental y a este tipo de disposiciones relacionales, pudiendo abrir espacios a conceptos de ciudadanía planetaria; así puede adoptar posición en temas relevantes como cambio climático (ESPINOZA, 2018), o sobre el sistema de evaluación de impactos ambientales (DONOSO, 2018), e incluso en un contexto político global; en consecuencia, ampliar hacia una participación en el contexto de la relación sociedad-naturaleza, comunidad planetaria, desde el supuesto de especie.

Otro tanto significa el debate sobre la relación derecho ambiental y derechos humanos, el que a pesar de consistir en una mirada posiblemente antropocéntrica, en cuanto derecho humano a vivir en un medio ambiente sano, también se abre a una perspectiva de unión de la sociedad-naturaleza-naturaleza-sociedad, como una manera de integrar y profundizar en esta área y que podría irradiar a todas las ciencias jurídicas. Así lo trata la Constitución Política del Estado Plurinacional de Bolivia en su art. 33, 
donde expresa que no solo las personas tienen este derecho, sino otros seres vivos, a desarrollarse de manera normal y permanente. Todo lo cual implica nuevos ámbitos relacionales entre sujetos, los que desbordan tal o cual disciplina jurídica

Estas reflexiones son momentos teóricos de mayor grado de integración como despliegue de un pensamiento complejo, es decir, como aquel que relaciona el todo y la parte no linealmente; por cuanto ya están en la esfera de las ciencias jurídicas y del jurista como teórico como productor de conocimiento jurídico y no sólo en el ámbito del legislador o del derecho. A pesar de estas innovaciones que deberán ir profundizándose debido a las necesidades del mundo actual, aún se requiere de una reflexión esencial y relacional desde la Filosofía, que revise las bases del conocimiento jurídico, en lo que respecta la relación sociedad-naturaleza-naturaleza-sociedad y que avance a un movimiento dialéctico de síntesis.

\section{LA SÍNTESIS: EL ENVERDECIMIENTO DE LAS CIENCIAS JURÍDICAS: UN SALTO CUALITATIVO}

Uno de los temas que Capra ha venido desarrollando desde el enfoque de la complejidad, es el de cómo algunas disciplinas científicas, que él pone de ejemplo, cambian desde enfoques clásicos mecanicistas a otros complejos y sistémicos. Así la Economía, ha transitado desde una fase simplificadora y reduccionista, que ha desconocido "que su ciencia no es más que un aspecto de toda una estructura ecológica y social, un sistema viviente formado de seres humanos que se relacionan continuamente entre sí y con los recursos naturales, que, a su vez, son también organismos vivientes" (CAPRA, 1998, p. 213); hasta enfoques más integrales, al igual que otras ciencias sociales. En la Psicología ha seguido en su primera fase al paradigma cartesiano, culminando con el enfoque mecanicista del conductismo, hasta tendencias actuales con enfoques integrales de la nueva psicología, lo que algunos comienzan a situar desde la Gestalt; y de igual manera el área de la salud y medicina con el paso de sus paradigmas biomédicos al biopsicosocial.

De igual manera todas las ciencias que han seguido de alguna manera el modelo newtoniano mecanicista para configurar a sus objetos de estudios, han sufrido revoluciones científicas y van asumiendo las perspectivas complejas sistémicas e inclusive, la asimilación de prácticas científicas 
interactuantes en equipos interdisciplinarios. Esto se debe entre algunas de las razones, a la necesidad de admitir, que los objetos de conocimiento están interconectados y que se afectan como sistemas sociales y naturales, lo que a su vez, han contribuido a inspirar las imágenes de realidad que la ciencia y sus paradigmas científicos, han producido (GÓMEZ, 2016). Considerando además, el aporte de las nuevas propuestas de las epistemologías que ya desde las últimas décadas del siglo XX, se han volcado al estudio sobre cómo se organizan las ciencias para la producción del conocimiento; ya sea sobre la base de consensos y/o paradigmas (KUHN, 2004), de Programas de Investigación Científica (LAKATOS, 1989) o bien, considerando la perspectivas sociológicas de las comunidades científicas $^{4}$. Esto adquiere relevancia, para desnaturalizar y deconstruir las formas de organizar la información y elaboración de teorías.

Ahora bien, se espera que las ciencias jurídicas logren replantear sus bases y que vayan superando la perspectiva newtoniana a nuevas alternativas, con emergentes y plurales saberes jurídicos; que no sólo asuman la importancia de comprender la identidad e indivisibilidad de la relación sociedad-naturaleza-naturaleza-sociedad como realidad compleja y sistémica, sino que a su vez, revisen categorías que la niegan o simplemente obstaculizan este avance, como lo son los portadores reducidos de sujetos y bases individualizadoras y antropocéntricas abusivas.

Este estadio de la relación sociedad-naturaleza-naturaleza-sociedad, ha provocado cambios epistemológicos en las ciencias (GÓMEZ, 2016) y de igual manera en el ámbito del Derecho como objeto de estudio de las ciencias jurídicas. Sin embargo, para estas últimas, como parte de un saber científico histórico, ha resultado débil el impacto de la crisis de la relación sociedad-naturaleza. En especial, en lo que respecta la revolución de modelos teóricos y enfoques jurídicos como la manera de crear conocimiento, estructurar, organizarlo y pensarlo.

\section{LAS CIENCIAS JURÍDICAS HAN REPRODUCIDO EN EL DERECHO, LA IMAGEN CIENTÍFICA CLÁSICA DE MUNDO}

Qué se entiende por relación sociedad-naturaleza-naturaleza-sociedad, y por qué ello se representa como un ámbito de contradicción humano-no humano, es un tema que hoy está en pleno debate. Las ciencias jurídicas

4 Entre algunos clásicos trabajos están los de Casas-Guerrero (1980). 
han traspasado al Derecho como su objeto de estudio, ciertas nociones de realidad que forman parte de la imagen del mundo. No es casual que la naturaleza y todos los no humanos sean considerados cosas apropiables, triturables, de los que se puede ejercer todos los atributos del dominio, usar, gozar y disponer.

\subsection{Las nociones de realidad que mantiene las ciencias jurídicas}

La ciencia no sólo es un saber eficaz que se plasma en productos, sino que también, es un saber que se estructura a través de lenguajes, imágenes, significados y valoraciones. Entre sus tareas más relevantes, está el haber producido una noción de realidad y que también las ciencias jurídicas comparten y reproducen traspasándola al Derecho. Ello se puede analizar tanto en la perspectiva del objeto de estudio, como su cualidad y en la forma de pensarlo. Así por ejemplo, la naturaleza ha quedado definida como la máquina que se descompone en partes atomizadas, lo que las ciencias jurídicas la asumen como cosas mueble; y por el otro lado, sólo reconoce al sujeto de derecho - personas- como las únicas que se consideran portadores de derechos subjetivos.

Por otra parte, el pensamiento clásico y método analítico que viene de la modernidad con Descartes, promueve la atomización y la noción que el todo es una suma de partes. Esa dinámica atomizadora, la lleva a dividir normas jurídicas y a reducir la dinámica del ordenamiento jurídico en partes desconectadas. Lo que comprende no sólo la cosificación de la naturaleza, sino que pensarla corporalizada y apropiablemente, como también a los seres humanos y sus derechos humanos, más que su connotación relacional, lo que podría llevar a un cambio jurídico paradigmático.

El mecanicismo que plantea a la realidad como una máquina compuesta de un sinnúmero de res extensa que se pueden descomponer y cosificar, reduce el derecho a cosas susceptibles de ser apropiadas, donde queda la naturaleza incluida como cosas inmuebles y muebles. Las ciencias jurídicas por su parte, le dan sustrato teórico a esas posibilidades resaltando por ejemplo, la figura de sujeto de derecho.

También el pensamiento jurídico objetual contribuye a concebir a la naturaleza como un conjunto divisible de cosas, y de esa forma lo protege: agua, mares, biodiversidad, bosques, clima, etc., lo que la mantiene como objetos de protección y una norma para cada tema, donde el Derecho ambiental es distinto al Civil, Penal, etc. Promueve la desconexión entre 
normas, ramas jurídicas, y a pensar las categorías relevantes, como realidades naturales reflejadas, es el caso de personas, sin comprender su complejidad jurídica (CORRAL, 1990).

Por el contrario, desde una base epistemológica como la teoría relacional, entendida según Lavanderos y Malpartida, como un sistema explicativo que fundamenta su operar en la relación como proceso de generación de sentido y mundo (LAVANDEROS; MALPARTIDA, 2005), la Naturaleza sería como señala Morin, una extraordinaria solidaridad de sistemas encabalgados edificándose los unos sobre los otros, por los otros, con los otros, contra los otros: la Naturaleza son los sistemas de sistemas, en rosario, en racimos, en pólipos, en matorrales, en archipiélagos (MORIN, 2017). Y si con ello se entrama la vida social, es de sumo relevante establecer bases para modelos y paradigmas ecojurídicos que transversalicen las ciencias jurídicas como un saber que pueda comprender y generar conocimiento nuevo integrado y sistémico.

Desde esta perspectiva de realidad, no se trata de cuidar y proteger a un otro, sino que de no producirlo, en tanto nueva cultura científica, como un otro. ${ }^{5}$ Digamos entonces, que la relación sociedad-naturaleza-naturaleza-sociedad como autoconciencia integradora desde un pensamiento jurídico relacional, debiera implicar el fin de la necesidad de la noción del antropocentrismo jurídico y de una base epistemológica clásica.

\subsection{Categorías jurídicas y principios: replanteamientos que se pueden asumir frente a esta desafiante realidad}

Al concebir la relación sociedad-naturaleza-naturaleza-sociedad como unidades relacionales se deja en claro sus difusas delimitaciones y nuevas nociones de la naturaleza de la condición social humana (MATURANA; VARELA, 2003). Difícil es diferenciar cuándo se está en presencia de lo social o natural, más bien es una dualidad que hoy no se puede seguir afirmando. Dicho así, ¿es posible seguir avalando categorías, modelos explicativos, dispositivos jurídicos de todo tipo que reproduzcan esta perspectiva y que en consecuencia sirvan de base a una ciencia jurídica antropocéntrica? Esta pregunta lleva a tener que revisar todas aquellas categorías, clasificaciones y relaciones, ya que en sus configuraciones está el sujeto presente como agente de control simbólico de producción

5 Como advierte en esa lógica Derrida en su libro "El animal que luego estoy si(gui)endo (DERRIDA, 2008). 
(BERNSTEIN, 1997). Pongamos por ejemplo la clasificación civil tan clásica y estudiada por generaciones que separan hechos de la naturaleza y del hombre, pues cómo responde a la pregunta ¿un aluvión propiciado por una deficiencia de la organización urbana que desconoce entre otros temas la memoria de un rio, es un hecho de la naturaleza o del humano?

Las ciencias jurídicas fueron moldeando su objeto de estudio -el derecho- de tal manera, que la dualidad humano-naturaleza aparecen como dos realidades en disputa. Sin embargo, la consideración de la Pachamama como un sujeto que se ha ido incorporando constitucionalmente por algunos países como Bolivia, implica un proceso de admitir nuevos sujetos de derecho. Este desafío representa un inyectar de sangre el cuerpo entero de las ciencias jurídicas y el derecho; lo enverdece, tanto en el ser del derecho, como en la forma pensarlo.

En tal sentido, no es sólo dable hacer una crítica a la manera de cómo la legislación aborda la consideración de la naturaleza, del animal y $\mathrm{Pa}$ chamama como una cosa, recurso natural, sino que el impacto fractal debe ser incalculablemente más profundo. Por ejemplo la lógica objetual de los bienes jurídicos propiedad, vida, salud, etc. deben ser revisados como valoración de ámbitos relacionales situacionales; en este sentido la lógica relacional del bien jurídico que plantea Juan Bustos es un aporte al pensamiento jurídico relacional (BUSTOS, 2005), abre la posibilidad de invisibilidad de la relación sociedad-naturaleza-naturaleza-sociedad como base para las configuraciones de bienes jurídicos.

La relación sociedad-naturaleza-naturaleza-sociedad planteada desde una conciencia jurídica crítica implica, que la dualidad creada por un proyecto de sociedad basado en el ideal de dominación de la naturaleza, puede y debe ser superada por otro, e impactar en lo jurídico, enverdecer a las ciencias jurídicas.

\section{ALGUNAS CONSIDERACIONES PARA ENVERDECER A LAS CIENCIAS JURÍDICAS}

\subsection{Incorporar saberes nuevos saberes plurales e inclusivos}

Se hace relevante reconocer una normatividad para enfrentar las nuevas dinámicas de comunidades sustentables, con dimensión pluralista, con principios de localismo, autonomía, diversidades, tolerancia. En especial, reconociendo como señala Wolkmer un pluralismo jurídico, inclusive 
planteado en términos de nuevo paradigma, que vaya recogiendo el derecho producido por la comunidad a partir de sus necesidades, en cuanto ruptura a la insuficiencia de la vertiente formal-positivista (WOLKMER, 2006). Donde lo inclusivo debe incorporar de manera más dialógica la relación sociedad-naturaleza y eso implementarlo en las bases de las ciencias jurídicas.

\subsection{El todo y la parte como momentos relacionales}

La promoción de pensamientos y perspectivas sistémicas ha favorecido la perspectiva del todo y la parte como momentos relacionales. Ya sea en el cómo afecta la parte al todo o bien, como este último está presente en la parte, según lo expresa el principio hologramático planteado para un pensamiento complejo por Morin (2002), y que podría apoyar al pensamiento jurídico como lo plantea Gómez (2012a). Esto se puede ejemplificar con la analogía del ADN, ya que, a pesar de su pequeñez, tiene la información de la totalidad; por lo tanto, el pensamiento jurídico debe hacer propuestas sobre instituciones e interpretaciones que relacionen y que puedan hacer apertura a miras sistémicas y a la integración indivisible de la relación sociedad-naturaleza.

Se puede decir que una norma en sí es insuficiente para resolver una causa, lo que se demuestra con modelos como el de la argumentación (ATIENZA, 2016), donde las lógicas de supremacía constitucional o control convencionalidad apelan a criterios de interconexión, donde los entramados confieren sentido jurídico. De manera que en contextos de globalización, hay que recuperar la noción de totalidad, pero que en la lógica actual, desde la perspectiva compleja, pasa por la construcción de universales pluralistas, ya que supone la unidad de lo diverso y de opuestos en interacción, pero no como externalidad, objetividad constatable, sino como posibilidad de aprehensión de los sistemas sociales y de acción (ESPINA, 2005).

Ello da cuenta de nuevas realidades que superan lo local y del cotidiano, del caso concreto, para pensar en lo global y viceversa a la vez. Tanto en consideración de los sistemas sociales y naturales. A su vez representa al sujeto individual y nuevos sujetos conversando jurídicamente, como por ejemplo Generaciones Futuras y mínimos sociales (GÓMEZ, 2018). 


\subsection{Nueva bioética}

Se hace necesario incorporar una nueva ética jurídica que provenga de una bioética global, recogiendo los aportes de Potter, uniendo las ciencias- humanidades y la relación cognición-valor (DELGADO, 2008); con nuevos principios de igualdad en la diversidad; que considere nuevas valoraciones para la relación sociedad-naturaleza, nuevas consideraciones morales y éticas en el macro contexto entre estos sistemas. Todo lo cual debe incorporarse en la valoración de selección de bienes jurídicos como replanteo global de protección del derecho.

\subsection{Nuevas categorías y nuevos sujetos}

Las categorías representan interacción sujeto-objeto, es decir no son meros conceptos, sino que provienen de la mediación con la realidad. De ahí que no son inventos meramente de juristas, por el contrario, tienen su base en la realidad desde un criterio práctico. De ahí entonces, a lo mejor, no se trate sólo de eliminar categorías obsoletas, sino que pueda haber una mayor consideración a las interrelaciones. Por ejemplo, nuevas relaciones entre el derecho subjetivo y otros que dan cuenta de lo social como las Generaciones Futuras; entre mujeres y mujer, entre comunidad indígena e indígena. Entre sistemas sociales y naturales de manera más entramada; lo que implica revisiones profundas a lo que significa derecho subjetivo humano-no humano; una justicia y principios eco-sociales; participación y ciudadanía eco-social.

Admitiendo entonces categorías más coherentes con la interrelación eco social. Una trama interconectada que dé un mayor torrente de sangre que corra por las venas de todo el derecho a través de una ciencia jurídica que cambie su paradigma antropocéntrico por uno eco relacional; en última instancia, enverdecer a las ciencias jurídicas.

\subsection{El derecho y la política}

La soberanía y su ejercicio se deben ejercer sobre la tierra. Y como patrimonio del sujeto humano-no humano como un nuevo ejercicio jurídico que tengan equilibrio entre lo universal-plural. Pero para ello se debe admitir la noción de especie -humana- como universal en trama de sobrevivencia, como ciudadano planetario, donde las Generaciones futuras 
podrían ser el límite de las acciones. Ello implica reconsiderar algunos de los aportes metodológicos del poder en Foucault (2019) y sus alcances a áreas de biopoder en el contexto de la relación humano-no humano (LÓPEZ, 2019).

\subsection{La nación con componentes cosmovisvos}

En definitiva, plantearse la importancia de la relación sociedad-naturaleza-naturaleza-sociedad como base del sujeto jurídico Generaciones Futuras. Los aportes de nuevas consideraciones como las planteadas por Malpartida y Lavanderos (1995), a través de lo que denominan ecotomo y que promueve una configuración relacional sistémica para reformular la unidad cultura-naturaleza.

Asimismo considerar a la relación sociedad-naturaleza-naturaleza-sociedad como contexto de crisis planetarias, pero en búsqueda de abrir esperanza de futuro. Esto es lo menos que puede hacer la Filosofía del derecho, de lo contrario, podría ser la orquesta del Titanic que toca la música a los poderosos, mientras los pobres morían ante un mar soberbio.

\subsection{Responsabilidad del jurista como actor social}

Las ciencias jurídicas no son neutrales y sus científicos deben ser agentes de cambios, lo que necesariamente, pasa por admitir su presencia en la elaboración del objeto de estudio con perspectivas relacionales sociedad-naturaleza-naturaleza-sociedad. Por ende, reducirlo sería una irresponsabilidad histórica. Un jurista no solo debe profundizar en las normas jurídicas, sino replantear los paradigmas y pensamientos, desde los cuáles, se relaciona con ellas.

\section{CONCLUSIONES}

El saber jurídico debe transformarse en un pensamiento crítico al interior de las ciencias jurídicas, aportando revisiones epistémicas profundas como también a sus axiomas, supuestos y en ello, a su propia organización.

Se reconoce que la relación sociedad-naturaleza-naturaleza-sociedad impacta en las sociedades actuales, de tal manera, que las ciencias jurídicas no están en condiciones de seguir con categorías insuficientes 
a las exigencias actuales y por el contrario, debe portar la identidad del humano-no humano en la producción de conocimiento jurídico.

Si bien el estadio de la relación sociedad-naturaleza-naturaleza-sociedad, ha afectado y tenido relevancia en el derecho, no es menos cierto que los paradigmas y las bases que sirven al conocimiento científico de las ciencias jurídicas, aún se ve poco comprometido en producir revoluciones científicas en su interior, inclusive de resaltar el prefijo eco.

Finalmente, la propuesta de enverdecer a las ciencias jurídicas, significa advertir, que la imagen del mundo clásico, ha servido para contribuir al ideal de dominación moderno sobre la naturaleza, lo que en términos de ciencias jurídicas, ha sido reproducido para crear y fundamentar paradigmas con esa orientación. Como al mismo tiempo, manifiesta una convocatoria, que desafía a las ciencias jurídicas, a abordar su producción científica-jurídica desde nuevos pensamientos jurídicos-complejos, con apertura a lo relacional de la sociedad-naturaleza- naturaleza-sociedad. Ello con la universalización y profundidad de transversalizar hacia nuevos modelos teórico-jurídicos, nuevos principios, instituciones y valoraciones.

Además y en especial, recordarle al jurista su responsabilidad histórica, más allá de las propias del legislador.

\section{REFERENCIAS}

ANDALUZ, C. Manual de Derecho Ambiental. Lima: Proterra, 2006.

ASTORGA, E. Derecho Ambiental. Santiago: Universidad Central de Chile, 2005.

ATIENZA, M. Derecho y argumentación. Lima: Palestra, 2016.

BADULES, D. El ecologismo como fundamento del derecho humano a un medio ambiente sano. Trabajo Final (Grado en Derecho) - Universidad Carlos III, Madrid, 2015.

BERNSTEIN, B. La estructura del discurso pedagógico. Madrid: Morata, 1997.

BUSTOS, J. Introducción al Derecho Penal. Bogotá: Temis, 2005.

CAFFERATTA, N. Introducción al Derecho Ambiental. México, DF: SEMARNAT/INE/PNUMA, 2004.

CAMACHO, C. Revisión del problema ambiental y su gestión. Poliantea, v. 6, n. 10, p. 11- 29, 2010. 
CAPRA, F. El punto crucial. Buenos Aires: Troquel, 1992.

CAPRA, F. La Trama de la vida: una nueva perspectiva de los sistemas vivos. Barcelona: Anagrama, 1998.

CASAS-GUERRERO, R. La idea de comunidad científica: su significado teórico y su contenido ideológico. Revista Mexicana de Sociología, v. XLII, n. 3, p. 1217-1230, 1980.

CORRAL, H. El concepto jurídico de persona: una propuesta de reconstrucción unitaria. Revista Chilena de Derecho, v.17, p. 301-321, 1990.

COSTA, E. La Justicia Ambiental en la evaluación de desempeño ambiental: Chile 2016 de la OCDE. Revista de Derecho Ambiental, v. 7, p. 94-113, 2017.

DELGADO, C. Hacia un nuevo saber, la bioética. Bogotá: Universidad El Bosque, 2008.

DERRIDA, J. El animal que luego estoy si(gui)endo. Madrid: Trotta, 2008.

DONOSO, A. Justicia ambiental y participación ciudadana en el Sistema de Evaluación de Impactos Ambientales. Revista de Derecho Ambiental, v. 10, p. 48-68, 2018.

ESPINA, M. Complejidad y pensamiento social. Revista Complexus, n. 1, mar. 2005.

ESPINOZA, A. Mecanismos de participación ciudadana en relación con los instrumentos internacionales de Cambio Climático. Revista de Derecho ambiental. v. 10, p. 26-47, 2018.

FERNÁNDEZ, P. Manual de Derecho Ambiental chileno. Santiago: Editorial Jurídica de Chile, 2004.

FERNÁNDEZ-RUBIO, Á. Derecho Ambiental Internacional contemporáneo. Curso a Distancia. CD-ROM. 2006.

FOUCAULT, M. Microfisica del poder. Buenos Aires: Siglo Veintiuno, 2019.

GARCÍA, R. Sistemas complejos. Barcelona: Gedisa, 2006.

GÓMEZ, T. La dualidad sujeto-objeto y sus repercusiones en el derecho. Revista Opinión Jurídica. v. 8, n. 15, p. 115-124, 2009.

GÓMEZ, T. La complejidad un nuevo paradigma para el derecho. Anuario 
de Filosofia Jurídica y Social. Valparaíso: Sociedad Chilena de Filosofía Jurídica y Social, Valparaíso, n. 29, p. 143-158, 2011.

GÓMEZ, T. Una visión hologramática del Derecho y su aporte a la investigación jurídica. Revista Frónesis, v. 19, n. 2, 2012a.

GÓMEZ, T. Crítica a la crítica del sistema punitivo: hacia una metacrítica. Revista Opinión Jurídica, v. 11, n. 21, p. 153-168, 2012 b.

GÓMEZ, T. La crisis ecosocial y su manifestación como epistemología: su relación con la complejidad - del ideal de dominación de la ciencia, al de sobrevivencia. Berlín: Editorial Académica Española, 2016.

GÓMEZ, T. Marx: la naturaleza y la modificación. Revista Nómadas, n. 48, p. 229-237, 2018.

KUHN, T. La estructura de las revoluciones cientificas. México, DF: Fondo de Cultura Económica, 2004.

LAKATOS, I. La metodología de los programas de investigación cientifica. Madrid: Alianza Universidad, 1989.

LAVANDEROS, L.; MALPARTIDA A. Teoría relacional de la comunicación como proceso eco_semio_auto poietico. Revista Complexus, v. 1, n. 2, p. 45-66, mar. 2005.

LORENZETTI, R. Teoría del Derecho Ambiental. México, DF: Porrúa, 2008.

LÓPEZ, J. I. Gubernamentalidad de la conservación: biopoder y tortugas marinas en México. Revista Latinoamericana de Estudios Críticos Animales, año VI, v. II, 2019.

MALPARTIDA, A.; LAVANDEROS, L. Una aproximación sociedad-naturaleza: el Ecotomo. Revista Chilena de Historia Natural, v. 68, p. 419-427, 1995.

MALPARTIDA, A. Lo obvio debe ser explicitado: la concepción relacional. Revista Complexus, v. 1, p. 47-57, dic. 2004.

MATURANA, H.; VARELA, F. El árbol del conocimiento las bases biológicas del Entendimiento humano. Buenos Aires: Lumen, 2003.

MATUS ACUÑA, J. P. et al. Análisis dogmático del Derecho Penal Ambiental Chileno, a la luz del Derecho Comparado y las obligaciones 
contraídas por Chile en el ámbito del Derecho Internacional: conclusiones y propuesta legislativa fundada para una nueva protección penal del medio ambiente en Chile. Revista Ius et Praxis, v. 9, n. 2, 2003.

MEDINA R.; AGUIRRE, G.; SARANGO, J. La responsabilidad civil en la prevención del medio ambiente y sus ecosistemas: una mirada desde el derecho privado", Universidad y Sociedad. v. 9, n. 1, p.173-177, 2017.

MORIN, E. El Método 1: la naturaleza de la naturaleza. Madrid: Cátedra, 2017.

MORIN, E. La cabeza bien puesta: repensar la reforma, repensar el pensamiento. Buenos Aires: Nueva Visión. 2002.

MORIN, E. Introducción al pensamiento complejo. Barcelona: Gedisa, 2003.

MOSCOSO, P. Principios de competencia judicial internacional y de protección del medio ambiente. Revista Ius Et Praxis, v. 17, n. 2, p. 283-304, 2014.

MUÑOZ, E. El medio ambiente como bien jurídico y derecho humano de tercera generación reconocido desde el imperio romano. DELOS: Desarrollo Local Sostenible, v. 7, n. 21, p. 83-102, 2014.

OBANDO-CAMINO, I. Desarrollo histórico legal de la jurisdicción arbitral de las organizaciones de usuarios de aguas en el Chile Republicano. Revista Agricultura, Sociedad y Desarrollo, v. 6, n. 3, p. 223-251, sep./dic. 2009.

OCHOA, A. Medioambiente como bien jurídico protegido, ¿visión antropocéntrica ecocéntrica?". Revista de Derecho Penal y Criminología, v. 11, p. 253-294, 2014.

SOTOLONGO, P.; DELGADO, C. La revolución contemporánea del saber y la complejidad social: hacia unas ciencias sociales de nuevo tipo. Buenos Aires: CLACSO, 2006.

VALLE, A. Enseñanza del Derecho, ¿Creencias O Competencias? Revista Escuela de Derecho, año 7, n. 7, p. 86, 2006.

VARELA, F. Conocer. Barcelona: Gedisa, 2006.

WOLKMER, A. Pluralismo jurídico: fundamentos de una nueva cultura del Derecho. Sevilla: MAD-Eduforma, 2006. 
ZAFFARONI, E. La Pachamama y el humano. Buenos Aires: Madres de Plaza de Mayo, 2011.

Artículo recibido en: 02/09/2019. Artículo aceptado en: 29/06/2020.

\section{Cómo citar este artículo (ABNT):}

GÓMEZ, T. R. Enverdecer las ciencias jurídicas desde el paradigma de la complejidad. Veredas do Direito, Belo Horizonte, v. 17, n. 38, p. XX-XX, mayo.-ago. 2020. Disponible en: http://www.domhelder.edu.br/revista/index.php/veredas/article/view/1644. Acceso: día de mes. año. 